\title{
Dealing with uncertainty in spatially explicit population models
}

\author{
THORSTEN WIEGAND ${ }^{1, *}$, ELOY REVILLA ${ }^{1,2}$ and FELIX KNAUER ${ }^{3,4}$ \\ ${ }^{1}$ Department of Ecological Modelling, UFZ-Centre for Environmental Research \\ Leipzig-Halle, PF 500136, D-04301 Leipzig, Germany; ${ }^{2}$ Department of Applied Biology, \\ Estación Biológica de Doñana CSIC, Avda. María Luisa s/n, E-41013 Seville, Spain; \\ ${ }^{3}$ Wildife Research and Management Unit, Faculty of Forest Sciences, Technical University \\ Munich, Linderhof 2, D-82488 Ettal, Germany; ${ }^{4}$ Current address: Alterra Green World \\ Research, P.O. Box 47, 6700 AA Wageningen, The Netherlands; *Author for correspondence \\ (e-mail: towi@oesa.ufz.de)
}

Received 10 June 2001; accepted in revised form 15 May 2002

\begin{abstract}
It has been argued that spatially explicit population models (SEPMs) cannot provide reliable guidance for conservation biology because of the difficulty of obtaining direct estimates for their demographic and dispersal parameters and because of error propagation. We argue that appropriate model calibration procedures can access additional sources of information, compensating the lack of direct parameter estimates. Our objective is to show how model calibration using population-level data can facilitate the construction of SEPMs that produce reliable predictions for conservation even when direct parameter estimates are inadequate. We constructed a spatially explicit and individual-based population model for the dynamics of brown bears (Ursus arctos) after a reintroduction program in Austria. To calibrate the model we developed a procedure that compared the simulated population dynamics with distinct features of the known population dynamics (=patterns). This procedure detected model parameterizations that did not reproduce the known dynamics. Global sensitivity analysis of the uncalibrated model revealed high uncertainty in most model predictions due to large parameter uncertainties (coefficients of variation $\mathrm{CV} \approx 0.8$ ). However, the calibrated model yielded predictions with considerably reduced uncertainty $(\mathrm{CV} \approx 0.2)$. A pattern or a combination of various patterns that embed information on the entire model dynamics can reduce the uncertainty in model predictions, and the application of different patterns with high information content yields the same model predictions. In contrast, a pattern that does not embed information on the entire population dynamics (e.g., bear observations taken from sub-areas of the study area) does not reduce uncertainty in model predictions. Because population-level data for defining (multiple) patterns are often available, our approach could be applied widely.
\end{abstract}

Key words: Individual-based model, Model calibration, Pattern-oriented modeling, Population dynamics, Spatially explicit population model, Uncertainty, Ursus arctos

\section{Introduction}

Over the last two decades the importance of spatial processes in population dynamics has been increasingly recognized, and the way that population 
dynamics are impacted by landscape structure has become a major subject of research and debate in ecology and conservation biology (e.g., see reviews of Dunning et al. 1992; Wiens et al. 1993; Fahrig and Merriam 1994). Habitat heterogeneity is believed to affect most aspects of the biology of a population and several theoretical constructs have been proposed for characterizing the impact of landscape structure on population dynamics (e.g., Fahrig and Merriam 1994). Clearly, the spatial structure of the landscape in which species are found must be explicitly considered when landscape composition and physiognomy play a role in determining population dynamics (Wiegand et al. 1999). For example, in many cases the quality and distribution of habitat is important for assessing viability of endangered species, for planning reintroduction programs (e.g., Schadt et al. 2002), or for managing expansion of large carnivores into new areas (e.g., Mladenoff et al. 1999). Spatially explicit population models (SEPMs) can provide a powerful tool for analyzing the impact of spatial processes and landscape structure on (meta)population dynamics (e.g., Dunning et al. 1995; Pulliam and Dunning 1995; Wiegand et al. 1999, 2004 (this issue)). These models often use a geographical information system (GIS) database to compile maps on habitat quality, and apply a population model that relates demographics of the species explicitly to the landscape in which the organism lives. Individual-based models allow for the inclusion of behavioral rules describing the response of individuals to the landscape and can link the individual's use of space (dispersal and habitat selection) directly to population and metapopulation phenomena (Lima and Zollner 1996; Wiegand et al. 1999). Consequently, SEPMs have been increasingly used in conservation as awareness of landscape processes has expanded and tools for analyzing landscape-scale phenomena have developed (Beissinger and Westphal 1998).

\section{Criticism of spatially explicit population models}

The initial enthusiasm about SEPMs (Pulliam and Dunning 1995), however, has been dampened by critical voices (e.g., Doak and Mills 1994; Ruckelshaus et al. 1997; Beissinger and Westphal 1998; Hartway et al. 1998) outlining the data requirements, problems associated with parameter estimation, and possible magnifications of parameter errors which may make the development of such models an onerous process (Kareiva et al. 1997; Beissinger and Westphal 1998). Most of the criticism of SEPMs is based on a series of articles (Wennergren et al. 1995; Meir and Kareiva 1997; Ruckelshaus et al. 1997; Hartway et al. 1998) in which the authors examined a simple spatially explicit model for organisms dispersing in a fragmented landscape. For example, the 'grim message' emerging from the analysis of 
Wennergren et al. (1995) was that "however appealing may be spatially explicit models of individual behavior, they are likely to be highly unreliable given our uncertainties about dispersal behavior and rates". This claim was later justified by the publication of the details of the model in Ruckelshaus et al. (1997). They found that errors due to uncertainty in a parameter describing per step mortality propagated into larger errors in predicted dispersal success. Although this key result turned out to be based on an erroneous analysis of the model (Mooij and DeAngelis 1999; Ruckelshaus et al. 1999), it captured well the spirit of general pessimism on the future of SEPMs. In fact, SEPMs seemed to be at a dead end. It was argued that even under the best circumstances, spatially explicit models may not be able to predict, with a reasonable certainty, the number of individuals in a landscape (Dunning et al. 1995; Beissinger and Westphal 1998).

\section{Pattern-oriented modeling and model uncertainty}

Clearly, for many applications in ecology and conservation biology there never will be enough data to produce accurate, direct field estimates of parameters related to demographics and dispersal. This is not because of insufficient data collection or data analysis techniques, but because of low individual numbers and the resulting high inherent stochasticity (Doak and Mills 1994; Beissinger and Westphal 1998). Also, it is true that no amount of clever modeling or detailed GIS habitat maps can circumvent the need of SEPMs for estimates of demographic and dispersal parameters (Ruckelshaus et al. 1999).

The point we want to make in this contribution is that parameters need not necessarily be estimated directly by field observations. Astute modeling can help to access other sources of data (e.g., population-level data such as time series) which can be used for indirect parameter estimation (Wiegand et al. 1998). Only recently, pattern-oriented modeling (Grimm 1994; Grimm et al. 1996; Wiegand et al. 2003) has been proposed as a framework for exploiting the available data at all steps of the modeling process: from the initial model construction to parameter estimation and to detection of deficiencies in the model structure and knowledge. The pattern-oriented modeling strategy relies on additional data contained in observed patterns which arise as high level output of population dynamics as a consequence of the interaction of all processes of population dynamics and constraining factors such as management actions (e.g., release of individuals, or hunting), or landscape structure. In conservation biology, such patterns comprise, for example, presence-absence data in patchy populations (e.g., Hanski 1994), or time-series of the size of a fraction of the population [e.g., the number of females with cubs in Wiegand 
et al. 1998, 2004 (this issue)]. These patterns are a rich source of data which is usually not used in population models because it cannot be directly translated into estimates of model parameters or included into the rule set of a population model. The data of such patterns, however, may help us to determine a correct model structure and parameter values indirectly, and is the key for addressing problems associated with uncertainty.

To reveal the 'hidden' data it is important to have a 'structurally realistic' model that (1) matches the predominant scales of the real system to facilitate a direct comparison of model relations with observations, and which (2) contains a 'correct' representation of the basic processes and interactions that determine the dynamics of the system on the given scales (DeAngelis and Mooij 2003). A systematic comparison of the observed pattern with patterns produced by different modifications of the model will detect implausible model parameterizations (e.g., Wiegand et al. 1998) or model structures (e.g., Jeltsch et al. 1999) and thus allows for adjustment of uncertain or unknown parameters or processes, avoiding error propagation. In structurally realistic models one can compare model predictions and internal model relations with empirical data, which adds further possibilities for evaluating model performance. Validation and exhaustive sensitivity analyses of SEPMs, however, have been rarely undertaken (but see Higgins et al. 2000; McCarthy et al. 2000; Rushton et al. 2000), mainly because of the computational effort involved, and because results can be difficult to interpret.

In this article we used the expansion of brown bears (Ursus arctos) into the eastern Alps (Wiegand et al. 2004 (this issue)) as an example of dealing with uncertainty in SEPMs. We show how one can obtain a credible SEPM without access to direct field estimates of most model parameters. We constructed a structurally realistic model that includes data on demographic processes, social structure, and dispersal behavior of brown bears. The model synthesizes knowledge that has been accumulated over many years of research on brown bear populations (e.g., summarized in Swenson et al. 2000). The specific aim of this model was to investigate population dynamics of brown bears in Austria after a reintroduction program, and to indirectly assess current key variables of population dynamics, such as population sizes and growth rates, dispersal distances, or mortality rates within different population nuclei (see Wiegand et al. 2004 (this issue)). Here we perform an extensive sensitivity analysis of the model and evaluate different populationlevel data sets (=patterns) in their ability to constrain model predictions. We show that a pattern (or a combination of several patterns) that embeds data on the entire population dynamics (a genuine pattern sensu Grimm et al. 1996) can reduce the uncertainty in model predictions substantially, and that model calibration with different genuine patterns yields consistent model predictions. 


\section{Methods}

Species and population: brown bears in the eastern Alps

After the extirpation of the last resident bear in southern Austria in 1884 (Rauer and Gutleb 1997), migrants from Slovenia reached Austria and Italy only sporadically. During 1989-1993 WWF Austria released three bears from Slovenia and Croatia (Rauer and Gutleb 1997), and in 1991 Slovenia banned the killing of bears outside of a core management area. This was of particular importance for bear recovery in Austria, because bears might now disperse unhindered from the large source population in southern Slovenia to Austria. Since then the subpopulation in central Austria has grown (Figure 1) and nine litters with a total of 23 cubs were observed between 1991 and 2000 (Rauer et al. 2001). Population estimates are about 25-30 bears in Austria (Zedrosser et al. 1999; Swenson et al. 2000).

\section{Model development}

The individual-based spatially explicit model and its development are fully described in Wiegand et al. (2004, this issue); here we provide only a brief description.

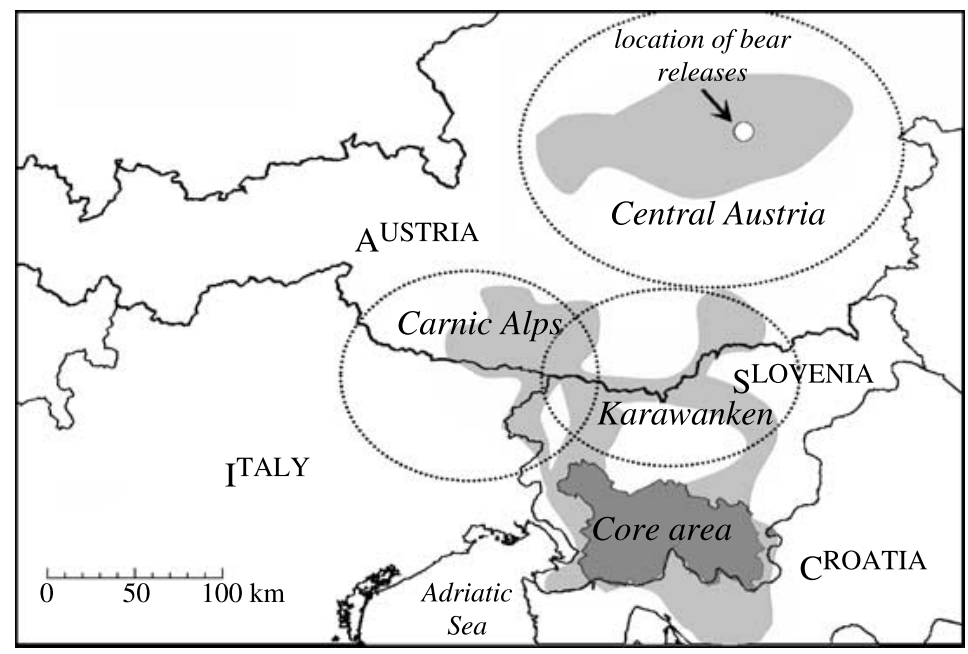

Figure 1. Schematic representation of brown bear observations in the eastern Alps after Kaczensky et al. (1996) and Swenson et al. (2000). Females in central Austria are isolated from females in northern Slovenia and southern Austria, but males from Slovenia are able to immigrate into central Austria. The ellipses encircle detailed study areas of the simulation model in central Austria, the Carnic Alps, and the Karawanken Mountains. The bear management core area in Slovenia is shown in dark gray color. 
Selection of scales. To model the size of a bear's home range we selected a $10 \mathrm{~km} \times 10 \mathrm{~km}$ raster-grid as spatial resolution of our model. This grain is slightly finer than the typical scale of an individual's home range, which can cover several hundred square kilometers in Austria (Rauer and Gutleb 1997; Kaczensky and Knauer 2000). We defined a square of nine cells $\left(\approx 900 \mathrm{~km}^{2}\right)$ as the maximum size of a female's home range, and a square of 36 cells $\left(\approx 3600 \mathrm{~km}^{2}\right)$ as the maximum size of a male's home range. Because males generally occupy home ranges several times larger than those of females and disperse considerably larger distances, we join a square of four cells to one 'virtual' cell and apply all the rules for male dispersal and establishment of home ranges on this double scale.

The habitat model. An important ingredient that constrains the spatial dynamics of the bear population is the habitat model that designates each $10 \mathrm{~km} \times 10 \mathrm{~km}$ raster cell an index value $Z$ of habitat quality, which ranged from $Z=0$ (completely unsuitable) to $Z=9$ (highest suitability). The map of habitat quality defined the landscape in which individuals were allowed to disperse, settle, reproduce, and die. The original habitat model was developed with data from 1947 radiolocations of 23 bears that were trapped between 1993 and 1998 in Slovenia (Kaczensky et al. 2000) and applied to the area of the whole eastern Alps (Figure 3 in Wiegand et al. 2004 (this issue)). Validation of the habitat model with an independent data set of five bears in central Austria (Rauer and Gutleb 1997) and an additional validation in Wiegand et al. (2004, this issue) using all bear observations in Austria showed that the best areas in the habitat model are indeed areas where bears were observed.

Demographic model. The demographic model determined the fates of individuals throughout life and simulated the life-history events of birth, independence, and death, as well as dispersal of young individuals and reproduction for adults. Each of these demographic events was determined stochastically. Mortality was modified as a function of home range size, and only females occupying a home range could reproduce. We did not consider temporal environmental variation because it is low for the long-lived brown bears (Sæther et al. 1998; Wiegand et al. 1998), and because we focused more on spatial than on demographic aspects.

Spatial submodel. We modeled only the dispersal movement of non-resident bears; movement of residents and dependent cubs within their home ranges was neglected. To include a process that describes spacing of home ranges and attraction of dispersing males by females in a simple but reasonable way, we introduced a variable termed habitat attractiveness that describes the attraction of a given $10 \mathrm{~km} \times 10 \mathrm{~km}$ cell for dispersing males and females. 
For empty cells, the attractiveness was given through the index of habitat suitability $Z$, but for females it was reduced when the cell was already within the home range of other individuals. For males the attractiveness is increased when more than one female occupied the cell (for details see Wiegand et al. 2004 (this issue)).

After independence, non-resident bears dispersed and searched for their own home range. They were allowed every year to perform $S_{\max }$ site-sampling steps and moved one grid cell per step, selecting a neighboring cell at random with a probability directly proportional to the attractiveness of the cell, relative to that of the other neighboring cells. We assumed a per step mortality rate $m_{\mathrm{s}}$ during dispersal. Movement stopped when the individual found an acceptable home range. A potential home range was acceptable if the sum of the attractiveness of a selection of cells taken from the nine cells, comprising the actual location of the individual and its eight neighboring cells, exceeded a threshold $A_{\text {min }}$ Surviving individuals that did not find a home range continued to disperse in the next year.

Because individuals with larger home ranges had to move more compared to individuals with smaller home ranges, we assumed that the age-dependent risk of mortality declined for resident individuals with a factor $\left(c_{\mathrm{m}}+\left[1-c_{\mathrm{m}}\right]\right.$ $[s / 9])$ if the size $s$ of their home range was smaller than nine cells. The parameter $c_{\mathrm{m}}$ defined the degree of reduction of mortality due to smaller home ranges. For non-resident independent bears mortality was the same as for residents with maximal home range size (i.e., $s=9$ ).

Bear management. The bear releases and the data on the fate of the two released females are important constraining factors in central Austria. Since we know exactly what happened to these bears, we included them in the model deterministically. In the model we released bears of the same age and sex as those in the wild, in the same area (1989 a 3-year-old female, 1991 a 6-yearold pregnant female, and 1993 a 4-year-old male), and we included the three litters and the subsequent death of the two released females deterministically.

One management parameter that influences immigration into Austria and Italy is the annual probability $J$ of bears being hunted outside the core area in Slovenia. To model the management practice before 1992 we assumed hunting as an additional annual risk of mortality $J<1$ independent of age or sex. In the case of protection outside the core area in Slovenia (the current management practice), we set $J=0$.

The dynamics of bears in the core area in Slovenia was not within the scope of our model. We therefore included only the source function of the core area, which is important for our aim. To this end we placed each year on average $s^{\mathrm{F}}$ females and $s^{\mathrm{M}}$ males at random locations at the northern border of 
the core area (Figure 1) and simulated their dispersal into northern Slovenia and Austria.

\section{Conventional determination of parameter values}

Wiegand et al. (2004, this issue) determined the values that are directly accessible from data from Austria and Slovenia (distribution of litter sizes, age of first reproduction, interbirth interval). For parameters on dispersal, and establishment of home ranges, these authors used the sparse data available from Austria and restricted the range of these parameters additionally with data on brown bears in Scandinavia and from other sources (e.g., Swenson et al. 2000). For constraints of the values of the unknown mortality rates they used data from Scandinavia (Sæther et al. 1998), northern Spain (Wiegand et al. 1998), and data from Yellowstone National Park, Wyoming, USA (summarized in Wiegand et al. 1998). Other unknown parameters, such as the number of immigrants from the core area in Slovenia into northern Slovenia, or the effect of home range size on mortality, were varied over a wide range. A complete listing of all model parameters and their ranges is given in Wiegand et al. (2004, this issue: Table 1).

\section{Model calibration using population-level data}

We used two data sets from field observations on brown bears in Austria, Slovenia, and Italy for model calibration. The first data set was a 10-years time series from central Austria of females with cubs of the year (Figure 2A), the second was the bear observation data set (Figure 2B) which was

Table 1. The 13 model parameters and their ranges. $J$ : hunting mortality in Slovenia before $1992, s^{\mathrm{F}}, s^{\mathrm{M}}$ : mean number of females and males leaving the core area per year, $a$ : parameter describing home range overlap, $A_{\mathrm{min}}^{\mathrm{F}}$ and $A_{\mathrm{min}}^{\mathrm{M}}$ : attractiveness threshold for acceptance of female and male home ranges, $S_{\max }^{\mathrm{F}}$ and $S_{\max }^{\mathrm{M}}$ : maximum number of site sampling steps per year for females and males, $c_{\mathrm{m}}$ : impact of home range size on mortality, $m_{i}$ : annual mortality rate at age $i, m_{\mathrm{s}}$ : per step risk of mortality during dispersal.

\begin{tabular}{lllllllllllllll}
\hline Parameter & $J$ & $s^{\mathrm{F}}$ & $s^{\mathrm{M}}$ & $a$ & $A_{\min }^{\mathrm{F}}$ & $A_{\min }^{\mathrm{M}}$ & $S_{\max }^{\mathrm{F}}$ & $S_{\max }^{\mathrm{M}}$ & $c_{\mathrm{m}}$ & $m_{0}$ & $m_{1-4}$ & $m_{5-17}$ & $m_{\mathrm{s}}$ \\
\hline $\begin{array}{l}\text { Range } \\
\text { min }\end{array}$ & 0.04 & 0.0 & 0 & 0.1 & 49 & 50 & 5 & 10 & 0 & 0.2 & 0.08 & 0.08 & 0.001 \\
$\begin{array}{l}\text { Range } \\
\max \end{array}$ & 0.70 & 0.7 & 3 & 0.5 & 58 & 65 & 40 & 50 & 1 & 0.5 & 0.28 & 0.18 & 0.008 \\
\hline
\end{tabular}



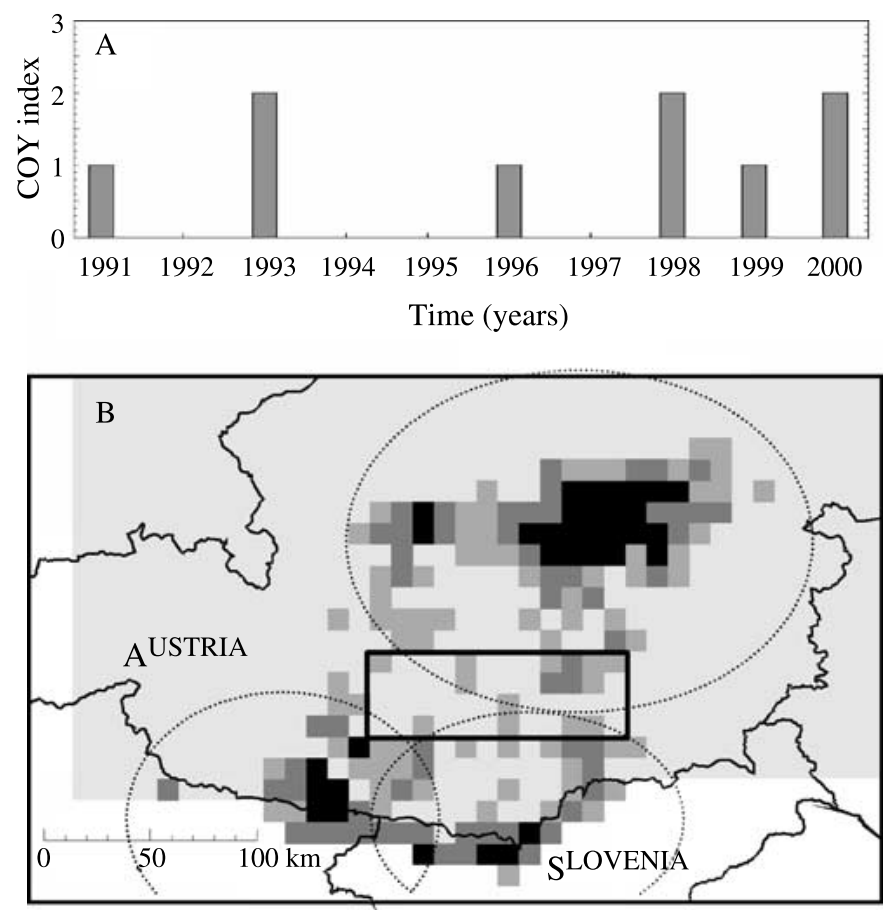

Figure 2. The patterns. (A) The time-series of females with cubs of the year (COY) in central Austria. Note that zero values indicate no observation, but not no data. (B) Data on bear observations classes from 1989 to 1999 transformed to the $10 \mathrm{~km} \times 10 \mathrm{~km}$ grid of the habitat model. White: no data, light gray: no observation, intermediate gray: sporadic observations (1-3), dark gray: regular observations (4-10), black: many observations $(>10)$. The black rectangle in the transition area between central and southern Austria encircles an area where no female bears were observed.

collected during the bear monitoring program in Austria (Rauer and Gutleb 1997; Rauer et al. 2001).

We grouped the data on bear observations within a $10 \mathrm{~km} \times 10 \mathrm{~km}$ cell into four coarse classes $(0,1-3,4-10,>10$ observations; Figure 2B). Although we cannot use the number of observations as a direct estimation of bear population size (e.g., Rauer and Gutleb 1997; Swenson et al. 1998), we assumed a higher density in cells with more observations. One problem with the number of observations is that more reports may come from areas that are just receiving their first immigrating bears because they are exciting and newsworthy. To improve this regional comparability, we did not compare observation data for the entire eastern Alps with simulated bear densities, but separately within the three subareas (central Austria, Carnic Alps, and Karawanken; Figure 1). No females were observed in the transition area between central and southern Austria (Figure 2B). We used this information as an additional pattern that 
indicated that females of the two subpopulations in southern Slovenia and central Austria were not linked.

In summary, for comparison between simulated and observed data we investigated five different observed patterns derived from the two data sets: (1) the low female density in the transition area between central and southern Austria (Figure 2B), (2-4) the observed bear density classes in central Austria, the Carnic Alps, and the Karawanken, respectively (Figure 2B), and (5) the time series of females with cubs (Figure 2A).

\section{Global sensitivity analysis and model predictions}

In Wiegand et al. (2004, this issue) we analyzed only model parameterizations that satisfied the pattern of females with cubs (Figure 2A), whereas here we aim to analyze the full behavior of the model by sampling the entire parameter space (i.e., a global sensitivity analysis). To this end we created model parameterizations by assigning random values for the 13 uncertain parameters, independently of each other, from uniform distributions within the ranges given in Table 1. The range of variation of each parameter reflects the degree of uncertainty in its estimate. For each model parameterization we performed as many replicate simulations as necessary to obtain 35 replicates in which the female population did not become extinct in central Austria. We neglected extinct replicates because females were present all years in central Austria. To investigate the sensitivity of the model output to the parameters, we calculated the mean values of 18 model predictions from the output of the 35 non-extinct replicate simulations (Table 2). We then performed multiple linear regressions with each model prediction as the dependent variable and the 13 parameters as independent variables (McCarthy et al. 1995). The resulting regression equation relates the parameters of the population model to predicted variables of population dynamics. Because we sampled the parameter space randomly, multicollinearity did not occur.

We scaled the dependent and independent variables to values between 0 and 1 and used the resulting coefficients $\beta_{i}$ of the linear regression as indices of the sensitivity of the model output to the parameters $p_{i}$. A coefficient $\left|\beta_{i}\right|=1$ indicates strong sensitivity, whereas parameters with small values $\left|\beta_{i}\right| \ll 1$ have little impact on the model prediction. To perform a rough sensitivity ranking of the model parameters $p_{i}$, we calculated the average of $\left|\beta_{i}\right|$ for all 18 model predictions.

\section{Impact of stochasticity on model predictions}

To obtain an estimate of the variation in the model predictions due to stochasticity, we repeated the procedure for determining model predictions 50 times 
Table 2. Model predictions investigated.

\begin{tabular}{|c|c|}
\hline Symbol & Meaning \\
\hline \multicolumn{2}{|c|}{ Residents } \\
\hline$N_{\text {total }}$ & Total population size in Austria and adjacent parts of Italy in 2000 \\
\hline$R_{\text {Kalk }}$ & Total number of residents in central Austria (see Figure 2) in 2000 \\
\hline$R_{\text {Carn }}$ & Total number of residents in the Carnic Alps (see Figure 2) in 2000 \\
\hline$R_{\text {Kara }}$ & Total number of residents in the Karawanken (see Figure 2) in 2000 \\
\hline \multicolumn{2}{|c|}{ Mean flux } \\
\hline Flux $^{\mathrm{M}}$ & Net annual flux of males from Austria to Slovenia (immigrants-emigrants) \\
\hline Flux $^{F}$ & $\begin{array}{l}\text { Net annual flux of females from Austria to Slovenia } \\
\text { (immigrants-emigrants) }\end{array}$ \\
\hline \multicolumn{2}{|c|}{ Growth rates } \\
\hline$r_{\text {Lotka }}$ & $\begin{array}{l}\text { For Austria and adjacent parts of Italy, using mortality and } \\
\text { reproduction events }\end{array}$ \\
\hline$r_{\text {total }}$ & $\begin{array}{l}\text { For Austria and adjacent parts of Italy, using the 1995-2000 } \\
\text { population numbers }\end{array}$ \\
\hline$r_{\text {Kalk }}$ & Growth rate for central Austria using the 1995-2000 numbers of residents \\
\hline ext & Number of extinct replicate simulations \\
\hline \multicolumn{2}{|c|}{ Reproduction } \\
\hline$c_{0}$ & Mean number of cubs expected by a female cub \\
\hline$c_{3}$ & Mean number of cubs expected by a subadult female of 3 years \\
\hline \multicolumn{2}{|c|}{ Dispersal } \\
\hline$d_{\text {mean }}^{\mathrm{M}}$ & $\begin{array}{l}\text { Mean dispersal distance [in } 10 \mathrm{~km} \text { ] (mother home range to own home } \\
\text { range) for males }\end{array}$ \\
\hline$d_{\text {mean }}^{\mathrm{F}}$ & $\begin{array}{l}\text { Mean dispersal distance [in } 10 \mathrm{~km} \text { ] (mother home range to own home } \\
\text { range) for females }\end{array}$ \\
\hline$d_{95}^{\mathrm{M}}$ & $95 \%$ percentile [in $10 \mathrm{~km}$ ] of male dispersal distances \\
\hline$d_{95}^{\mathrm{F}}$ & $95 \%$ percentile [in $10 \mathrm{~km}$ ] of female dispersal distances \\
\hline $\mathrm{md}_{14}^{\mathrm{M}}$ & Mean dispersal mortality for males in age class $1-4$ years \\
\hline $\mathrm{md}_{14}^{\mathrm{F}}$ & Mean dispersal mortality for females in age class $1-4$ years \\
\hline
\end{tabular}

with the same model parameterization. We assessed the impact of stochasticity on model predictions for six model parameterizations which were randomly chosen among the 10 best. For each model parameterization we calculated the resulting mean (mean) and standard deviation (SD) of the 50 replicate estimations for each model prediction. We used the average of the 
coefficients of variation $\mathrm{CV}=\mathrm{SD} /$ mean of the six model parameterizations to reflect uncertainty due to stochasticity.

\section{Model calibration: systematic comparison between observed and simulated patterns}

In this step patterns produced by the model are systematically compared with the patterns observed in the field. To assess whether or not simulated patterns match an observed pattern, we need to measure the deviation $E$ between the patterns, and we need a criterion to define confidence intervals for accordance between the patterns. This criterion acts as a 'filter' for implausible model parameterizations.

Measure to compare the pattern of females with cubs. To measure the deviation between one simulated time series $S(t)$ of females with cubs at years $t=1991-2000$ with the corresponding data $[D(t)]$ we used the measure

$$
E^{\mathrm{cub}}=\sqrt{\frac{1}{10} \sum_{t=1991}^{2000}\left[\frac{D(t)+D(t-1)}{2}-\frac{S(t)+S(t-1)}{2}\right]^{2}},
$$

which is basically the sum of squares of the 2-year running mean of the two time series [note that $S(1990)=0, D(1990)=0$ ], but for better interpretation we transformed it to be analogous to the standard deviation. We chose the 2year running mean to capture the population trend, because females in central Austria appear to have a 2-year interbirth interval. To compare the 35 replicate simulations for each model parameterization to the observed pattern, we use the average $E_{35}^{\text {cub }}$ of the 35 resulting error indices $E^{\text {cub }}$.

We defined an acceptance threshold for $E_{35}^{\text {cub }}$ using a randomization approach, and compared $E_{35}^{\text {cub }}$ to a null model of random litters. For this purpose we created 35 random time series by distributing six litters between 1994 and 2000 at random and including the three litters of the two released females deterministically. For these 35 random time series we calculated the resulting average error index $E_{35}^{\text {random }}$ analogously to the calculation of $E_{35}^{\text {cub }}$. We repeated this procedure 5000 times to obtain the distribution of $E_{35}^{\text {random }}$ and use the criterion that $E_{35}^{\text {cub }}$ should be smaller than the corresponding mean deviation $E_{35}^{\text {random }}$ of $97.5 \%$ of the random time series. However, we cannot assume that each replicate simulation yields exactly six litters. We therefore repeated the above procedure four more times, but allowed additionally for random variation of the number of litters between 5-7, 4-8, 3-9, and 2-10.

Measure to compare patterns of relative bear densities. To compare the simulated bear densities with the observed density classes, we tested how 
they were correlated. Because we do not know the functional relationship between the simulated bear density and the bear observation class (except that it should be a monotonic relationship) we assumed three basic cases [a quadratic $(0,1,4,9)$, a linear $(0,1,2,3)$ and a scaled square-root $(0,7$, $10,12)$ relationship of the observation class to observed densities]. Because our data were not necessarily normally distributed, we determined the confidence interval, separately for each of the three functional relationships, using a permutation test (Higgins et al. 2000). We randomly permuted the spatial locations of the four observation classes within the given subarea and calculated the resulting correlation coefficient $r$. We repeated this procedure 10,000 times and determined the interval that covered $97.5 \%$ of all random correlation coefficients from the left tail of the distribution. We accepted a simulated pattern to accord with the observed pattern if the correlation coefficient for at least one functional relationship was outside this $97.5 \%$ confidence interval for random permutations.

Measure for the low female density in the transition area. In Wiegand et al. (2004, this issue) we performed simulations with 50 times more random model parameterizations and could thus use a restrictive criterion to test for low density of resident females $\left(F_{\mathrm{R}}<0.008\right)$ and dispersing females $\left(F_{\mathrm{D}}<0.004\right)$ in the transition area. The best parameterizations in Wiegand et al. (2004, this issue) yielded $F_{\mathrm{R}}=0.0074 \pm 0.0054$ females per $100 \mathrm{~km}^{2}$ and year, and $F_{\mathrm{D}}=0.0038 \pm 0.0032$ females per $100 \mathrm{~km}^{2}$ and year. Here we use a less restrictive criterion $\left(F_{\mathrm{R}}<0.012, F_{\mathrm{D}}<0.006\right)$ which covers this range approximately.

Which type of pattern data can be used for model calibration and does calibration with different patterns yield the same model predictions?

The basic assumption of our approach to model calibration was that the data of genuine patterns filter for implausible model parameterizations, thereby restricting the model predictions obtained from the remaining model parameterizations. This assumption leads to the question of how much additional data (in the form of additional patterns) would we need to calibrate a structurally realistic SEPM for obtaining precise predictions. A second important question is whether or not model calibrations with different patterns will lead to the same model predictions, that is, even if calibration with a given pattern yields precise model predictions (small variance), is there a bias? To answer these questions, we filter the $n=557$ model parameterizations that do not satisfy different combinations of our five patterns, investigate the precision of the model predictions based on the remaining model parameterizations, and check the model predictions for bias. 


\section{Results}

\section{Sensitivity analysis}

As expected from the large parameter uncertainty, model predictions varied over wide ranges (Table 3). This high uncertainty in model output was also reflected in the high standard deviation of the model predictions. We found that the multiple linear regression functions were highly significant $(p<0.0001)$ for all predictions, the residuals were normally distributed, and high $R^{2}$ values $\left(R^{2}>0.7\right)$ for most regressions (Table 3$)$ indicated that the linear regression models yielded good approximations.

We found a clear sensitivity ranking (Table 3). Calculation of the average sensitivity coefficient showed that the subadult mortality rate $m_{1-4}$ and the per step mortality rate $m_{\mathrm{s}}$ during dispersal were the most sensitive model parameters, followed by the number $s^{\mathrm{F}}$ of females leaving the core area in Slovenia, and the threshold $A_{\text {min }}^{\mathrm{M}}$ for acceptable male home ranges. All other parameters had only moderate or low sensitivities. The parameters with the lowest sensitivity were the impact of home range size on mortality $\left(c_{\mathrm{m}}\right)$, the cub mortality rate $m_{0}$, and the mortality rate $m_{5-17}$ of adult bears.

\section{Impact of stochasticity on model predictions}

Our model showed demographic stochasticity caused by the low individual numbers. For six model predictions $\left(r_{\text {Lotka }}, r_{\text {Kalk }}, d_{\text {mean }}^{\mathrm{M}}, d_{\text {mean }}^{\mathrm{F}}, d_{95}^{\mathrm{M}}, m d_{14}^{\mathrm{M}}\right)$ the coefficient of variation $\mathrm{CV}$ ranged below 0.05 , indicating a low impact of stochasticity. For seven predictions $\left(N_{\text {total }}, R_{\text {Kalk }}, R_{\text {Kara }}\right.$, Flux $\left.{ }^{\mathrm{M}}, c_{0}, c_{3}, d_{95}^{\mathrm{F}}\right)$ $\mathrm{CV}$ ranged between 0.05 and 0.1 , for four predictions $\left(R_{\text {Carn }}\right.$, Flux ${ }^{\mathrm{F}}, r_{\text {total }}$, $\mathrm{md}_{14}^{\mathrm{F}}$ ) it ranged between 0.1 and 0.2 , and for ext we found $\mathrm{CV}=0.3$. Thus, uncertainty in model predictions due to stochasticity was roughly one order of magnitude smaller than the variation in the predictions due to parameter uncertainty (Table 3 ).

\section{Measuring the concordance between observed and simulated patterns}

Measure to compare the pattern of females with cubs. We found that $97.5 \%$ of all randomly created time series yielded an error index $E_{35}^{\text {random }}>0.50$, $0.51,0.52,0.54$, and 0.56 , when varying the number of litters randomly between $6,5-7,4-8,3-9$, and 2-10, respectively. Wiegand et al. (2004, this issue) based the model calibration on $>28,000$ random model parameterizations and used the restrictive condition $E_{35}^{\text {cub }}<0.500$ to select the parameterizations that were better than a random pattern. Here we used only data derived from 557 random model parameterizations and employed the less 
Table 3. Sensitivity analysis of model predictions based on $n=557$ random model parameterizations. Given are the mean \pm the standard deviation, the minimum and the maximum value of the model prediction, the $R^{2}$ of the multiple linear regression with the prediction as dependent variable and the 13 model parameters as independent variables, and the resulting sensitivity coefficient $S$ for each model parameter. For symbols of model parameters and model predictions see Tables 1 and 2.

\begin{tabular}{|c|c|c|c|c|c|c|c|c|c|c|c|c|c|c|c|c|c|}
\hline \multirow[t]{2}{*}{ Prediction } & \multirow[t]{2}{*}{ Mean \pm SD } & \multirow[t]{2}{*}{ Min } & \multirow[t]{2}{*}{$\operatorname{Max}$} & \multirow[t]{2}{*}{$R^{2}$} & \multicolumn{13}{|c|}{ Sensitivity coefficient $S\left(=\beta_{\mathrm{i}}\right.$ ) for model parameters $i$} \\
\hline & & & & & $J$ & $s^{\mathrm{F}}$ & $s^{\mathrm{M}}$ & $a$ & $A_{\min }^{\mathrm{F}}$ & $A_{\mathrm{min}}^{\mathrm{M}}$ & $S_{\max }^{\mathrm{F}}$ & $S_{\max }^{\mathrm{M}}$ & $c_{\mathrm{m}}$ & $m_{0}$ & $m_{1-4}$ & $m_{5-17}$ & $1 / m_{\mathrm{S}}$ \\
\hline$N_{\text {total }}$ & $15.6 \pm 13.4$ & 1.7 & 92.9 & 0.69 & -0.12 & 0.19 & 0.09 & 0.00 & -0.01 & -0.14 & 0.01 & -0.04 & 0.00 & -0.03 & -0.23 & -0.04 & 0.24 \\
\hline$R_{\text {Kalk }}$ & $4.25 \pm 2.08$ & 1.37 & 17.11 & 0.76 & -0.04 & 0.06 & 0.06 & -0.09 & -0.03 & -0.21 & 0.04 & -0.02 & -0.02 & -0.05 & -0.23 & -0.04 & 0.19 \\
\hline$R_{\text {Carn }}$ & $1.96 \pm 1.60$ & 0.06 & 11.06 & 0.75 & -0.10 & 0.24 & 0.10 & -0.05 & -0.08 & -0.17 & 0.06 & -0.01 & -0.01 & -0.03 & -0.20 & -0.06 & 0.07 \\
\hline$R_{\text {Kara }}$ & $4.02 \pm 2.84$ & 0.06 & 20.51 & 0.75 & -0.09 & 0.22 & 0.10 & -0.12 & -0.07 & -0.15 & 0.05 & -0.02 & -0.01 & -0.02 & -0.17 & -0.05 & 0.05 \\
\hline Flux $^{\mathrm{M}}$ & $0.61 \pm 0.59$ & -0.01 & 3.11 & 0.71 & -0.10 & 0.19 & 0.28 & -0.02 & -0.04 & -0.08 & 0.01 & -0.14 & 0.00 & -0.03 & -0.10 & -0.02 & 0.46 \\
\hline Flux $^{\mathrm{F}}$ & $0.22 \pm 0.23$ & -0.01 & 1.39 & 0.71 & -0.18 & 0.32 & 0.10 & 0.03 & 0.01 & -0.07 & 0.05 & 0.00 & 0.00 & -0.05 & -0.22 & -0.05 & 0.13 \\
\hline$r_{\text {Lotka }}$ & $-0.019 \pm 0.087$ & -0.661 & 0.218 & 0.77 & -0.03 & 0.06 & 0.03 & -0.02 & 0.00 & -0.15 & -0.01 & -0.04 & 0.00 & -0.01 & -0.21 & -0.01 & 0.13 \\
\hline$r_{\text {total }}$ & $0.087 \pm 0.061$ & -0.098 & 0.249 & 0.74 & -0.03 & 0.21 & 0.02 & -0.05 & 0.00 & -0.18 & 0.01 & -0.06 & -0.03 & -0.06 & -0.38 & -0.08 & 0.14 \\
\hline$r_{\text {Kalk }}$ & $0.017 \pm 0.043$ & -0.114 & 0.157 & 0.71 & -0.04 & 0.08 & 0.03 & -0.07 & 0.02 & -0.24 & 0.04 & -0.07 & -0.02 & -0.06 & -0.30 & -0.10 & 0.19 \\
\hline ext & $28.6 \pm 17.7$ & 1.0 & 99.0 & 0.75 & 0.04 & -0.03 & 0.01 & 0.05 & 0.02 & 0.06 & -0.03 & 0.02 & 0.11 & 0.15 & 0.48 & 0.12 & -0.10 \\
\hline
\end{tabular}


Table 3. (continued)

\begin{tabular}{|c|c|c|c|c|c|c|c|c|c|c|c|c|c|c|c|c|c|}
\hline \multirow[t]{2}{*}{ Prediction } & \multirow[t]{2}{*}{ Mean \pm SD } & \multirow[t]{2}{*}{ Min } & \multirow[t]{2}{*}{ Max } & \multirow[t]{2}{*}{$R^{2}$} & \multicolumn{13}{|c|}{ Sensitivity coefficient $S\left(=\beta_{\mathrm{i}}\right.$ ) for model parameters $i$} \\
\hline & & & & & $J$ & $s^{\mathrm{F}}$ & $s^{\mathrm{M}}$ & $a$ & $A_{\min }^{\mathrm{F}}$ & $A_{\min }^{\mathrm{M}}$ & $S_{\max }^{\mathrm{F}}$ & $S_{\max }^{\mathrm{M}}$ & $c_{\mathrm{m}}$ & $m_{0}$ & $m_{1-4}$ & $m_{5-17}$ & $1 / m_{\mathrm{S}}$ \\
\hline $\mathrm{md}_{14}^{\mathrm{M}}$ & $0.39 \pm 0.22$ & 0.04 & 0.94 & 0.80 & -0.04 & 0.02 & 0.16 & 0.05 & -0.01 & 0.31 & -0.06 & 0.39 & -0.01 & 0.00 & -0.03 & -0.02 & -0.70 \\
\hline $\mathrm{md}_{14}^{\mathrm{F}}$ & $0.032 \pm 0.024$ & 0.000 & 0.147 & 0.65 & -0.11 & 0.19 & 0.06 & 0.14 & 0.11 & -0.09 & 0.19 & -0.02 & -0.03 & -0.04 & -0.15 & -0.06 & -0.32 \\
\hline$d_{\text {mean }}^{\mathrm{M}}$ & $9.7 \pm 2.4$ & 4.4 & 14.7 & 0.53 & -0.04 & 0.08 & 0.32 & 0.05 & -0.04 & 0.05 & 0.02 & -0.11 & -0.03 & 0.00 & -0.07 & -0.05 & 0.59 \\
\hline$d_{\text {mean }}^{\mathrm{F}}$ & $3.4 \pm 1.1$ & 1.0 & 6.7 & 0.83 & -0.14 & 0.34 & 0.10 & 0.26 & 0.19 & -0.10 & 0.20 & 0.00 & -0.02 & -0.03 & -0.23 & -0.06 & 0.14 \\
\hline$d_{95}^{\mathrm{M}}$ & $20.9 \pm 4.0$ & 7.0 & 27.0 & 0.45 & 0.01 & -0.02 & 0.24 & 0.03 & -0.02 & 0.05 & 0.02 & -0.14 & -0.04 & -0.01 & -0.04 & -0.03 & 0.46 \\
\hline$d_{95}^{\mathrm{F}}$ & $8.3 \pm 2.7$ & 2.0 & 16.0 & 0.78 & -0.13 & 0.34 & 0.10 & 0.17 & 0.19 & -0.08 & 0.24 & 0.01 & -0.03 & 0.00 & -0.19 & -0.05 & 0.12 \\
\hline$c_{0}$ & $0.98 \pm 0.40$ & 0.04 & 3.09 & 0.78 & -0.05 & 0.08 & 0.04 & -0.02 & -0.01 & -0.18 & -0.01 & -0.03 & -0.01 & 0.00 & -0.29 & -0.03 & 0.18 \\
\hline$c_{3}$ & $1.83 \pm 0.63$ & 0.14 & 4.33 & 0.79 & -0.10 & 0.16 & 0.08 & 0.00 & 0.01 & -0.26 & 0.03 & -0.05 & -0.01 & -0.02 & -0.24 & -0.05 & 0.19 \\
\hline \multicolumn{3}{|c|}{$\begin{array}{l}\text { Average sensitivity coefficient } \\
\text { of model parameters }\end{array}$} & & & 0.08 & 0.16 & 0.11 & 0.07 & 0.05 & 0.14 & 0.06 & 0.06 & 0.02 & 0.03 & 0.21 & 0.05 & 0.24 \\
\hline
\end{tabular}



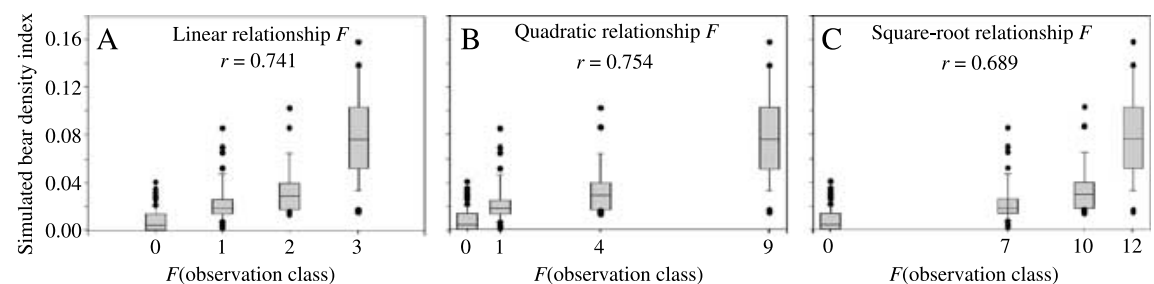

Figure 3. Calculation of the correlation coefficients $r$ to measure the deviance between the observed bear densities and the simulated bear densities [bears $/ 100 \mathrm{~km}^{2}$ year], shown for one model parameterization and the area of central Austria. (A) Quadratic relationship of the observation class to observed densities, (B) linear relationship, and (C) scaled square-root relationship. The observation classes are: no observation (class 0$), 1-3$ observations (class 1 ), 4-10 observations (class 2), and $>10$ observations (class 4). Boxes summarize median and the inner $50 \%$, whiskers the inner $80 \%$ of the simulated data, and points show the data outside the inner $80 \%$ of the data.

restrictive criterion $E_{35}^{\text {cub }}<0.52$ to obtain a reasonable sample size. However, model predictions and their standard deviations were in general not sensitive to the selection of the threshold of $E_{35}^{\text {cub }}$ (see also Wiegand et al. 2004 (this issue)).

Measure to compare patterns of relative bear densities. All three monotonic relationships were sufficient to capture the possible relations between observed and simulated bear densities. For example, the quadratic relationship provided the best approximation to the simulated bear density data in central Austria (Figure 3), and yielded the highest correlation coefficient $r$. Our permutation test yielded $97.5 \%$ thresholds cor $=0.25,0.20$, and 0.21 for central Austria, the Carnic Alps, and the Karawanken, respectively. The simulated bear densities were, on a $97.5 \%$ confidence level, different from a random distribution of bear observations if the correlation coefficients yields $r>$ cor. The threshold cor did not differ between the three functional relationships $F$.

\section{Systematic comparison between observed and simulated patterns}

We found that only $12(\approx 2 \%)$ of our $n=557$ parameterizations accorded with the observed time series of females with cubs (Table 4). By calculating the correlation coefficients between observed and simulated bear densities we found generally high correlation coefficients that were above the threshold cor of a random pattern. We therefore used a more restricted criterion which selected the best model parameterizations for each subarea (Table 4). The information that female densities should be low in the transition area between central and southern Austria sorted out only 9\% of all model parameterizations. 
Table 4. Filters defined through observed patterns. $F_{\mathrm{D}}, F_{\mathrm{R}}$ : mean simulated density of dispersing and resident females, respectively, within the box shown in Figure 2B; $r$ : correlation between bear observation class and simulated bear density; $E_{35}^{\text {cub }}$ : error index between observed and simulated time series of females with cubs.

\begin{tabular}{llll}
\hline Filter description & Filters & Condition & $\begin{array}{l}\text { Number of model } \\
\text { parameterizations } \\
\text { in accordance with } \\
\text { observed pattern }\end{array}$ \\
& & & 557 \\
\hline No filter & 0 & - & 506 \\
Density of females in transition area & 1 & $F_{\mathrm{D}}<0.006$ & $F_{\mathrm{R}}<0.012$ \\
Bear observations in central Austria & 2 & $r>0.72$ & 138 \\
Bear observations in the Carnic Alps & 3 & $r>0.62$ & 154 \\
Bear observations in the Karawanken & 4 & $r>0.63$ & 180 \\
Females with cubs & 5 & $E_{35}^{\text {cub }}<0.52$ & 12 \\
& $2+3$ & & 63 \\
& $2+4$ & & 33 \\
& $3+4$ & & 50 \\
& $2+3+4$ & & 13 \\
& $5+1$ & & 11 \\
\hline
\end{tabular}

Which type of pattern data can be used for model calibration and does calibration with different patterns yield the same model predictions?

We examined how the application of different combinations of the five filters (Table 4) increases the precision of model predictions (Figure 4). Although the application of filters 2, 3, or 4 individually filtered out some $75 \%$ of the model parameterizations, none of them reduced the high uncertainty in the model predictions as indicated by the high coefficient of variation (Figure 4). None of them introduced a strong bias in the model predictions. In contrast, filter 5 (the time series of females with cubs) substantially reduced the variation in the model predictions (Figure 4). However, we found that the joined application of the three filters $(2+3+4)$ yielded basically the same estimates for model predictions as the application of filter 5 and reduced the coefficient of variation considerably (Figure 4). Thus the key result of our analysis showed that the data for each of the three subareas taken together, restricted the model performance as well as the single 'strong' filter of the time series of females with cubs. This means that the quite different data on spatial bear observations and on the temporal time series of females with 

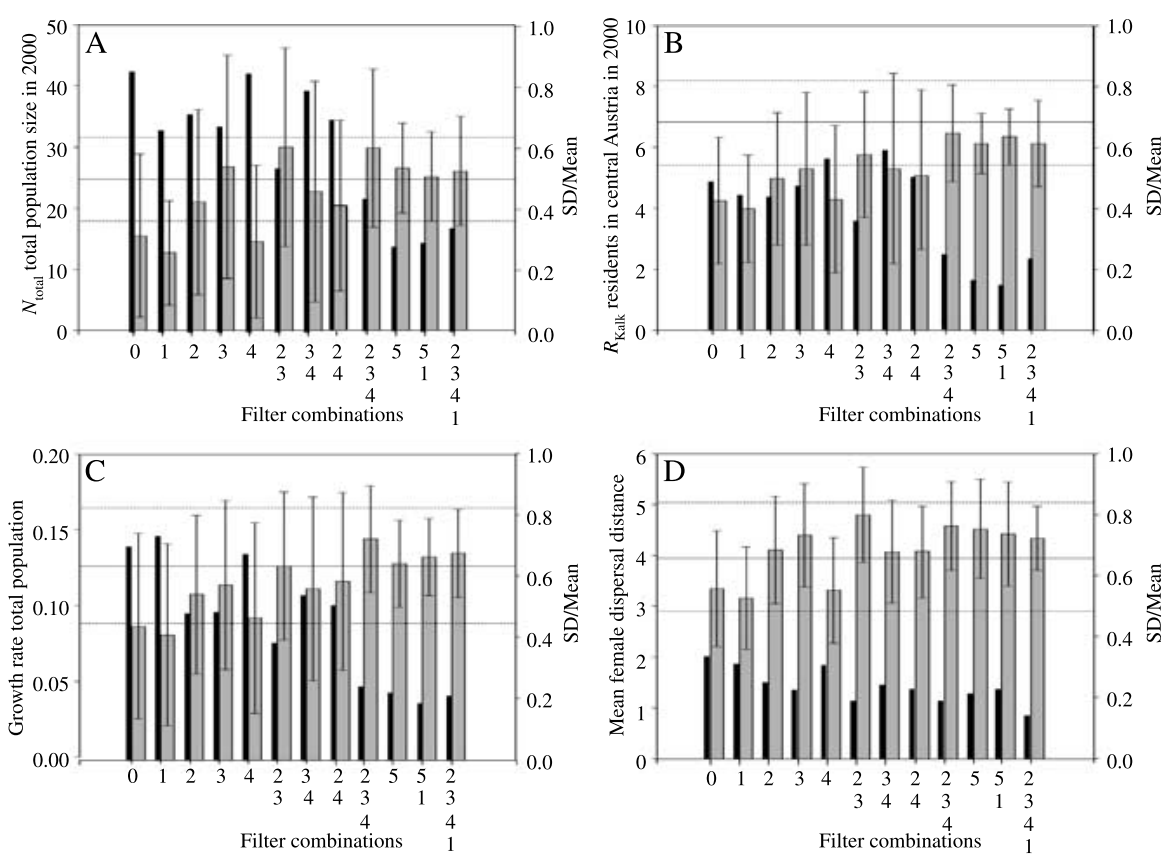

Figure 4. Application of the five filters (Table 4) alone and in combination and restriction of model predictions. The gray bars give the mean value of the prediction based on the $n$ model parameterizations that passed the filters $1-5$ and their combinations ( $x$-axis). The error bars give the standard deviation, and the black bars show the coefficient of variation (SD/mean). The horizontal lines give the estimate of the predictions from Wiegand et al. (2004, this issue) (solid horizontal) and the envelopes of the standard deviations (dashed horizontals) which were based on 50 times more random model parameterizations and a more restricted filter criterion.

cubs deliver consistent model predictions. Alternatively, we can argue that one data set provided the model calibration and the other the successful model validation. Filter 1 (low female densities in the transition area between central and southern Austria), however, provided little additional information (cf., filter 5 with $5+1$ and $2+3+4$ with $2+3+4+1$ in Figure 4). The result that even a relatively low number of $n=557$ random model parameterizations of 13 model parameters yielded estimates of model predictions that did not differ from the estimates with 50 times greater simulation effort (Figure 4) is worth mentioning.

\section{Discussion}

Our results support further enthusiasm for using SEPMs in conservation biology and we contradict the pessimism articulated by some authors (e.g., Wennergren et al. 1995; Ruckelshaus et al. 1997; Beissinger and Westphal 
1998). Although we agree with their argument that uncertainty of model parameters and processes can cause severe problems for model reliability, we do not share their conclusion that SEPMs may have little practical benefit in conservation biology. We constructed a SEPM without access to direct estimates of most demographic parameters. Following the recommendations in Beissinger and Westphal (1998), this exercise would be a waste of resources because it is "composed of many times more variables parameterized with educated guesses than with data from field measurement". Indeed, the predictions of our uncalibrated model varied over wide ranges. However, our method for model calibration used a wide range of data, not just direct estimates of parameters. The additional data was embedded in high level patterns of population dynamics and was sufficient to reduce the high uncertainty in model predictions due to uncertainty in model parameters. However, it is important to note that we do not advocate to abolish conventional data collection for direct parameter estimation. Model construction and parameterization should be based, as much as possible, on direct data, but observed patterns can provide additional data if this is not possible.

Surprisingly, spatially explicit models are rarely calibrated in ecology and especially not in conservation biology (but see Hanski 1994; Wiegand et al. 1998; Jeltsch et al. 1999; Lindenmayer et al. 2000; McCarthy et al. 2000) since model calibration with independent data sets is standard practice in many areas (e.g., fisheries modeling, climate modeling, hydrology). Mathematical modelers have increasingly used quantitative statistical techniques for confrontation between models and data and to make rigorous inference from biological patterns (e.g., Hilborn and Mangel 1997; Kendall et al. 1999; Wood 2001; Turchin 2003).

\section{Sensitivity analysis}

The high sensitivity of the mortality rate $m_{1-4}$ (which includes breeding females of ages 3 and 4) is in accordance with results of a sensitivity analysis of a demographic non-spatial model for brown bears in Wiegand et al. (1998) and accords with results from other demographic models (e.g., Gaona et al. 1998). The high sensitivity of SEPMs to a parameter describing mortality during dispersal was recently pointed out by Ruckelshaus et al. (1997). In our model, only predictions that are directly related to the dispersal process $\left(\right.$ Flux $\left.^{\mathrm{M}}, \mathrm{md}_{14}^{\mathrm{M}}, \mathrm{md}_{14}^{\mathrm{F}}, d_{\text {mean }}^{\mathrm{M}}, d_{95}^{\mathrm{M}}\right)$ show a high sensitivity to dispersal parameters. This sensitivity, however, does not translate into high variation of predictions on a higher level of population dynamics (i.e., growth rates or population sizes). This finding contradicts frequent criticism against SEPMs and is in accordance with a recent analysis of South (1999). 
The high sensitivity to the number $s^{\mathrm{F}}$ of females leaving the source (core area) in Slovenia is caused by the spatial population structure. The relatively high sensitivity to the threshold $A_{\min }^{\mathrm{M}}$ for acceptable male home ranges is partly due to the high uncertainty in this parameter and the fact that it is directly related to the carrying capacity of the landscape. At first view, the low sensitivity indices of adult mortality rates are surprising. However, the reasons for the relatively weak impact of $m_{5-17}$ are the fact that the mortality rate $m_{1-4}$ already includes breeding females, the specific demographic situation of the small population after the reintroduction, and the high proportion of subadult immigrants (see Figure 6A in Wiegand et al. 2004 (this issue)).

\section{Gains of pattern-oriented modeling}

There are basically three types of epistemic uncertainty in data for population models: (1) uncertainty in the formulation of the biological processes ('structural uncertainty'), (2) uncertainty in the values of the parameters of the processes (parameter uncertainty), and (3) natural stochasticity (environmental and demographic stochasticity) (e.g., Burgman and Possingham 2000). While natural stochasticity has to be considered, astute modeling can substantially reduce structural uncertainty and parameter uncertainty.

Because the biology of brown bears, and many other species, is well known, we could construct a structurally realistic model with relatively low structural uncertainty. However, our uncalibrated model produced high variations in model predictions due to large uncertainties in parameter values (Figure 4) and, to a lesser extent, due to natural stochasticity. But we showed that the data embedded in different high level patterns of population dynamics (i.e., the number of females with cubs, and spatial bear observations) improved precision and consistency of the model greatly. Importantly, these patterns stem from data that are commonly (and relatively easy) collected during monitoring programs. It was reassuring that application of different patterns (i.e., filter $2+3+4$, and filter 5) yielded the same model predictions. If the model structure is correct, then different high level patterns of population dynamics should be redundant because they are different manifestations of the same processes and the extra data can be used for model validation. In contrast, if model predictions differ after application of different filters then the model structure and/or the model parameterization are deficient.

Whereas it might be relatively simple to reproduce one feature of a system, the simultaneous fulfillment of several patterns describing different features of the system is by far non-trivial. A reproduction (or 'explanation') of one pattern with a model does not guarantee that the model actually identified the processes or mechanisms responsible for the patterns in reality (Levin 1992; Moloney 1993; Jeltsch et al. 1999). Therefore, a critical assessment 
of whether or not a pattern is genuine is needed (Grimm et al. 1996). The quantitative data of the time series of females with cubs encapsulate data on demographics and population sizes in central Austria and on immigration to this subpopulation and is thus a genuine pattern. The filters $2-4$ and their joint applications (i.e., $2+3,3+4$, or $2+4$ ), however, are only fragmentary data on relative bear densities within restricted areas. For this reason we cannot expect them to adjust the spatiotemporal dynamics of the population model within the entire study area, because they leave too many degrees of freedom uncovered. However, an important result of our analysis is that the combination of several 'weaker' patterns (i.e., $2+3+4$ ) can provide the same data as one 'strong' pattern (i.e., filter 5) if they together cover the essential aspects of population dynamics. Our technique is therefore especially powerful when multiple patterns are used (see also Kendall et al. 1999; Railsback and Harvey 2002). If the model is able to reproduce multiple patterns, each getting a different feature of the system, the risk that the model or the model parameterization would be wrong is lower than when relying only on one pattern (Kendall et al. 1999).

When several patterns exist that constrain the performance of the model in the same way, one may ask to what extent this information may be used for further model refinement. At this point one has to be realistic about structural uncertainty and natural stochasticity, and about the uncertainty in the pattern itself (i.e., measurement error). We investigated stochasticity in our model predictions by repeating model runs with the same model parameterization and found that the standard deviation of the model predictions was typically about $10 \%$ of the mean, while the remaining uncertainty of the model predictions, after applying the filters, yielded standard deviations that were typically $20 \%$ of the mean of the model predictions (Figure 4). Therefore we cannot improve the model performance substantially without improving the structural realism and reducing the measurement error of the patterns.

\section{Conclusions}

In the past, several authors outlined the tremendous energy that is invested in developing SEPMs and they argued that this research will never produce reliable guidance for conservation unless funds and human resources are expended on producing accurate, direct field estimates of dispersal rates and dispersal survival (e.g., Wennergren et al. 1995; Meir and Kareiva 1997; Ruckelshaus et al. 1997; Beissinger and Westphal 1998). The results of our analysis, however, show that this conclusion is wrong. In many cases, such as for brown bears, however, the biology of the species is very well known and SEPMs that incorporate this data (i.e., structurally realistic models) can 
allow for a deep analysis of the dynamic of the species and for consistent predictions, even without accurate, direct field estimates of parameters on mortality, dispersal, and reproduction rates. The key to deal with uncertainty in spatially explicit models (and indeed in any simulation model) is how, and how much of the available data are used. In this article we demonstrated the self-evident fact that we can only make reliable predictions if we have sufficient data. However, the difference to conventional approaches is that the data can be provided by one or more high level patterns of population dynamics instead of being a direct field measurement of a model parameter.

\section{Acknowledgements}

Funding provided by the UFZ-Centre for Environmental Research, Leipzig enabled authors to travel between Germany, Slovenia, and Spain for co-operative work. Funding by the International Bureau of the BMBF (AUS 00/Q02) allowed T.W. to attend the fragmentation workshop in Robertson, NSW, Australia. E.R. was supported by a Marie Curie Fellowship from the European Commission (Energy, Environment and Sustainable Development Contract EVK2-CT-1999-50001). The authors thank J. Camarero, K. Henle, S. Higgins, F. Palomares, S. Schadt, W. Schröder, A. Tyre, and C. Wissel for assistance during the development of ideas or for comments on earlier drafts of this manuscript, and especially M. Burgman, D. DeAngelis, and B. Melbourne for critical and thorough comments and reviews which markedly improved the content and tone of this manuscript.

\section{References}

Beissinger S.R. and Westphal M.I. 1998. On the use of demographic models of population viability in endangered species management. Journal of Wildlife Management 62 : 821-841.

Burgman M. and Possingham H.P. 2000. Population viability analysis for conservation: the good, the bad and the undescribed. In: Young A.G. and Clarke G.M. (eds), Genetics, Demography and Viability of Fragmented Populations. Cambridge University Press, London, pp. 97-112.

DeAngelis D.L. and Mooij W.M. 2003. In praise of mechanistically-rich models. In: Canham C., Cole J.J. and Lauenroth W. (eds), Models in Ecosystem Science. Princeton University Press, Princeton, New Jersey.

Doak D.F. and Mills L.S. 1994. A useful role for theory in conservation. Ecology 75: 615-626.

Dunning J.B., Danielson B.J. and Pulliam H.R. 1992. Ecological processes that affect populations in complex landscapes. Oikos 65: 169-175.

Dunning J.B., Stewart D.J., Danielson B.J., Noon B.R., Root T.L., Lamberson R.H. et al. 1995. Spatially explicit population models: current forms and future uses. Ecological Applications 5: 3-11. 
Fahrig L. and Merriam G. 1994. Conservation of fragmented populations. Conservation Biology 8: 50-59.

Gaona P., Ferreras P. and Delibes M. 1998. Dynamics and viability of a metapopulation of the endangered Iberian Lynx (Lynx pardinus). Ecological Monographs 68: 349-370.

Grimm V. 1994. Mathematical models and understanding in ecology. Ecological Modelling 75/76: 641-651.

Grimm V., Frank K., Jeltsch F., Brandl R., Uchmanski J. and Wissel C. 1996. Pattern-oriented modelling in population ecology. The Science of the Total Environment 183: 151-166.

Hanski I. 1994. A practical model of metapopulation dynamics. Journal of Animal Ecology 63: $151-162$

Hartway C., Ruckelshaus M. and Kareiva P. 1998. The challenge of applying spatially explicit models to a world of sparse and messy data. In: Bascompte J. and Solé R.V. (eds), Modeling Spatiotemporal Dynamics in Ecology. Springer-Verlag and Landes Bioscience, Berlin, Germany, pp. 215-223.

Higgins S.I., Richardson D.M. and Cowling R.M. 2000. Using a dynamic landscape model for planning the management of alien plant invasions. Ecological Applications 10: $1833-1848$.

Hilborn R. and Mangel M. 1997. The Ecological Detective: Confronting Models with Data. Princeton University Press, Princeton, New Jersey.

Jeltsch F., Moloney K.A. and Milton S.J. 1999. Detecting process from snap-shot pattern: lessons from tree spacing in the southern Kalahari. Oikos 85: 451-467.

Kaczensky P. and Knauer F. 2000. Habitat use of bears in a multi-use landscape. In: Kaczensky P. (ed), Co-existence of Brown Bear and Man in the Cultural Landscape of Slovenia. Report of the Institute of Wildlife Biology and Game Management at the Agricultural University of Vienna, Austria.

Kaczensky P., Knauer F., Huber T., Jonozovic M. and Adamic M. 1996. The LjubljanaPostojna highway - a deadly barrier for brown bears in Slovenia? Journal of Wildlife Research 1: 263-269.

Kaczensky P., Knauer F., Jonozovic M., Walzer C. and Huber T. 2000. Experiences with trapping, immobilization and radiotagging of brown bears in Slovenia. In: Kaczensky P. (ed), Co-existence of Brown Bear and Man in the Cultural Landscape of Slovenia. Report of the Institute of Wildlife Biology and Game Management at the Agricultural University of Vienna, Austria.

Kareiva P., Skelly D. and Ruckelshaus M. 1997. Reevaluating the use of models to predict the consequences of habitat loss and fragmentation. In: Pickett S.T.A., Ostfeld R.S., Shachak H. and Likens G.E. (eds), The Ecological Basis for Conservation. Chapman \& Hall, New York, pp. 156-166.

Kendall B.E., Briggs C.J., Murdoch W.W., Turchin P., Ellner S.P., McCauley E. et al. 1999. Why do populations cycle? A synthesis of statistical and mechanistic modeling approaches. Ecology 80: 1789-1805.

Levin S.A. 1992. The problem of pattern and scale in ecology. Ecology 73: 1943-1967.

Lima S.L. and Zollner P.A. 1996. Towards a behavioral ecology of ecological landscapes. Tree 11: 131-135.

Lindenmayer D.B., Lacy R.C. and Pope M.L. 2000. Testing a simulation model for population viability analysis. Ecological Applications 10: 580-597.

McCarthy M.A., Burgman M.A. and Ferson S. 1995. Sensitivity analysis for models of population viability. Biological Conservation 73: 93-100.

McCarthy M.A., Lindenmayer D.B. and Possingham H.P. 2000. Testing spatial PVA models of Australian treecreepers (Aves: Climacteridae) in fragmented forest. Ecological Applications 10: 1722-1731. 
Meir E. and Kareiva P. 1997. Contributions of spatially explicit landscape models to conservation biology. In: Fiedler P.L. and Kareiva P. (eds), Conservation Biology for the Coming Decade. 2nd edn. Chapman \& Hall, New York, pp. 497-507.

Mladenoff D.J., Sickley T.A. and Wydeven A.P. 1999. Predicting gray wolf landscape recolonization: logistic regression models vs. new field data. Ecological Applications 9: $37-44$.

Moloney K.A. 1993. Determining process through pattern: reality or fantasy? In: Levin S.A., Powell T.M. and Steele J.H. (eds), Lecture Notes in Biomathematics Vol. 96. SpringerVerlag, New York, pp. 61-69.

Mooij W.M. and DeAngelis D.L. 1999. Error propagation in spatially explicit population models: a reassessment. Conservation Biology 13: 930-933.

Pulliam H.R. and Dunning J.B. 1995. Spatially explicit population models. Ecological Applications 5: 2.

Railsback S.F. and Harvey B.C. 2002. Analysis of habitat-selection rules using an individualbased model. Ecology 83: 1817-1830.

Rauer G.B. and Gutleb 1997. Der Braunbär in Österreich. Monographie. Federal Environment Agency - Austria, Vienna, Austria.

Rauer G.B., Aubrecht P., Gutleb B., Kaczensky P., Knauer F., Plutzar C. et al. 2001. Der Braunbär in Österreich II. Vol. M-110. Federal Environment Agency, Vienna, Austria.

Ruckelshaus M., Hartway C. and Kareiva P. 1997. Assessing the data requirement of spatially explicit dispersal models. Conservation Biology 11: 1298-1306.

Ruckelshaus M., Hartway C. and Kareiva P. 1999. Dispersal and landscape errors in spatially explicit population models: a reply. Conservation Biology 13: 1223-1224.

Rushton S.P., Barreto G.W., Cormack R.M., Macdonald D.W. and Fuller R. 2000. Modelling the effects of mink and habitat fragmentation on the water vole. Journal of Applied Ecology 37: 475-490.

Schadt S., Revilla E., Wiegand T., Knauer F., Kaczensky P., Breitenmoser U. et al. 2002. Assessing the suitability of central European landscapes for the reintroduction of Eurasian lynx. Journal of Applied Ecology 39: 189-203.

Sæther B.-E., Engen S., Swenson J.E., Bakke Ø. and Sandegren F. 1998. Viability of Scandinavian brown bear Ursus arctos populations: the effects of uncertain parameter estimates. Oikos 83: 403-416.

South A. 1999. Dispersal in spatially explicit population models. Conservation Biology 13: 1039-1046.

Swenson J.E., Sandegren F. and Söderberg A. 1998. Geographic expansion of an increasing brown bear population: evidence for presaturation dispersal. Journal of Animal Ecology 67: 819-826.

Swenson J.E., Gerstl N., Dahle B. and Zedrosser A. 2000. Action plan for the conservation of the brown bear (Ursus arctos) in Europe. Council of Europe, Report T-PVS (2000) 24.

Turchin P. 2003. Complex Population Dynamics: A Theoretical/Empirical Synthesis. Princeton University Press, Princeton, New Jersey.

Wennergren U., Ruckelshaus M. and Kareiva P. 1995. The promise and limitations of spatial models in conservation biology. Oikos 74: 349-356.

Wiegand T., Naves J., Stephan T. and Fernandez A. 1998. Assessing the risk of extinction for the brown bear (Ursus arctos) in the Cordillera Cantabrica, Spain. Ecological Monographs 68: 539-571.

Wiegand T., Moloney K.A., Naves J. and Knauer F. 1999. Finding the missing link between landscape structure and population dynamics: a spatially explicit perspective. The American Naturalist 154: 605-627. 
Wiegand T., Jeltsch F., Hanski I. and Grimm V. 2003. Using pattern-oriented modeling for revealing hidden information: a key for reconciling ecological theory and application. Oikos 100: 209-222.

Wiegand T., Knauer F., Kaczensky P. and Naves J. 2004. Expansion of brown bears (Ursus arctos) into the eastern Alps: a spatially explicit population model. Biodiversity and Conservation 13: 79-114 (this issue).

Wiens J.A., Stenseth N.C., van Horne B. and Ims R.A. 1993. Ecological mechanisms and landscape ecology. Oikos 66: 369-380.

Wood S.N. 2001. Partially specified ecological models. Ecological Monographs 71: 1-25.

Zedrosser A., Gerstl N. and Rauer G. 1999. Brown Bears in Austria. Vol. M-117. Federal Environment Agency, Vienna, Austria. 